\title{
O CARÁTER E VALORES DA REFORMA E DO PACTO EDUCACIONAL NO GOVERNO DE GOIÁS, 2011-2014
}

Sérgio Inácio do NASCIMENTO

Divina Aparecida Leonel LUNAS ${ }^{2}$

\begin{abstract}
${ }^{1}$ Bolsista Capes; Mestrando do Mestrado Interdisciplinar Territórios e Expressões Culturais no Cerrado - Universidade Estadual de Goiás - Câmpus Anápolis de Ciências Sócio-Econômicas e Humanas; E-mail: sergioinacio@ globo.com

${ }^{2}$ Universidade Estadual de Goiás - Câmpus Anápolis de Ciências Sócio-Econômicas e Humanas - Pró-Reitoria de Pesquisa, Doutora em Desenvolvimento Econômico pela Unicamp - SP - Professora do Mestrado Interdisciplinar Territórios e Expressões Culturais no Cerrado - UEG - Bolsista do Programa de Incentivo ao Pesquisador - BIP Orientadora do primeiro autor. E-mail: divalunas@gmail.com
\end{abstract}

Recebido em: 18/10/2015 - Aprovado em: 03/01/2016 - Disponibilizado em: 30/07/2016

\begin{abstract}
Resumo
Este artigo procura analisar a ideologia e os valores que serviram de guia para a Reforma e o Pacto Educacional na educação básica no governo estadual de Goiás de 2011-2014, na administração do governador Marconi Perillo (PSDB). No início de 2011, Thiago Peixoto assume a Secretaria Estadual de Educação de Goiás, tendo como lema a promessa de campanha do senador Marconi Perillo, eleito nas eleições de outubro de 2010 governador de Goiás, que seu governo seria o governo da educação. O documento de apresentação da Reforma Educacional apresentado pela Secretaria Estadual de Educação de Goiás possui cinco pilares norteadores do Pacto Educacional com 25 diretrizes orientadoras. A configuração da Reforma Educacional através de seu plano, programas, projetos, em seus pilares organizou-se em um sentido, tendo para cada pilar estratégico, metas definidas para a educação básica de Goiás, consonância e uma sintonia da reforma educacional com a ideologia e os valores do capitalismo.
\end{abstract}

Palavras-chave: Reforma. Pacto. Educação. Capitalismo.

\begin{abstract}
This article aims to analyze the ideology and values that served as a guide for Reform and Educational Pact in basic education in Goiás state government of 2011-2014, in the administration of Governor Marconi Perillo (PSDB). In early 2011, Thiago Peixoto assumes the state Department of Education of Goiás, having as a motto the promise of Senator Marconi Perillo's campaign, elected in the October 2010 elections as governor of Goiás, that his government would be the governance of education. The Education Reform presentation document submitted by the State Department of Education of Goiás has five guiding pillars of the Educational Pact with 25 guidelines. The configuration of the Educational Reform through its plan, programs, projects, its pillars organized in one direction, having for each strategic pillar, defined goals for basic education in Goiás, consonance and symphony of educational reform with the ideology and the values of capitalism.
\end{abstract}

Keywords: Reformation. Pact.Education.Capitalism.

\section{INTRODUÇÃO}

O objetivo deste artigo é analisar a ideologia e os valores que serviram de guia para a Reforma e o Pacto Educacional na educação básica no governo de Goiás: 20112014. Escolheu-se método dialético para a realização deste estudo. Destacando as contradições como o motor da mudança social e da história. Entendendo que as ideias, as concepções, os gostos, as crenças, categorias do conhecimento e ideologias, geradas socialmente, dependem do modo como os homens se organizam para produzir e fazer politica. Mesmo o pensamento e a consciência são consequência da relação homem/natureza, 
ou seja, das relações matérias, das relações de produção.

No início de2011, Thiago Peixoto assume a Secretaria Estadual de Educação de Goiás tendo como lema a promessa de campanha do governador Marconi Perillo, que seu governo seria o governo da educação. Foi feito um diagnóstico e elaborou-se com sua equipe no decorrer do ano de 2011, um plano de reforma da educação pública básica em Goiás. As principais justificativas eram as carências apresentadas pela educação pública em Goiás.

De acordo com a visão de Thiago Peixoto e tendo como referência a necessidade de mudança, posta no documento que trata da Reforma Educacional em Goiás, o contexto descrito, faz observações de alguns elementos, tais como: a) um dos fatores que colaborampara o baixo desempenho, é o alto número de abandono dos estudantes no percorrer da educação básica; b) no ensino médio a cada 100 discentes matriculados, 27 largam os estudos; c) verificou-se que nos últimos anos do ensino fundamental, de cada 100 alunos 21 abandonam as salas de aulas.

No entendimento de Peixoto o Índice de Desenvolvimento da Educação Básica (Ideb) era considerado o mais importante indicador de qualidade no processo de ensino e aprendizagemno Brasil. Em 2005 Goiás estava na $7^{\mathrm{a}}$ posição com 3,91 nos anos iniciais do $1^{\mathrm{o}}$ ao $5^{\mathrm{o}}$ ano, caindo para a $8^{\mathrm{a}}$ posição em 2007 com 4,27, tendo mantido a mesma posição com 4,90 em 2009. Do $6^{\circ}$ ao $9^{\circ}$ ano caiu-se da $10^{\circ}$ posição em 2005 com 3,29para em 2007 um patamar de 3,45 de $13^{\circ}$ posição, no ano de 2009 foi para $15^{\circ}$ posição com 3,59. No ensino médio, também ocorreu queda, em 2005 estava-se na $13^{\circ}$ colocação com2,86 indo para a $16^{\circ}$ posição com 2,82 em 2007 e na sequência em 2009 mante-se na mesma posição com 3,07. A partir desta avaliação e outros dados, a Secretaria de Educação de Goiás elaborou diretrizes abrangentes com cinco pilares: 1) valorização e fortalecimento do profissional da educação; 2) uso de práticas de ensino de grande influência no aprendizado do estudante; 3) diminuição expressiva da desigualdade educacional; 4) estruturação de um método de reconhecimento e remuneração por mérito, 5) execução de intensa reforma na administração e na infraestrutura nas unidades escolares da rede estadual de ensino (Secretaria Estadual de Educação, 2015) .

$\mathrm{Na}$ estrutura deste escrito temos uma introdução e mais três seções. Na introdução apresentamos o objetivo desta reflexão e o objeto de estudo. Na primeira seção debruçase sobre os pilares e as diretrizes da reforma educacional. $\mathrm{Na}$ segunda verificam-se as consonâncias da reforma e do pacto educacional com o capital e termina-se com as considerações finais. 
OS PILARES E AS DIRETRIZES DA REFORMA E DO PACTO EDUCACIONAL

O documento de apresentação da Reforma Educacional possui cinco pilares norteadores do Pacto Educacional, com 25 diretrizes orientadoras, que serão observadas em alguns de seus pontos relevantes. A configuração da Reforma Educacional em seus pilares organizava-se em um sentido tendo para cada pilar estratégico metas definidas para a educação básica de Goiás. $\mathrm{O}$ primeiro pilar foi apresentado tendo como o objetivo valorizar e fortalecer o profissional da educação. Nesta questão, a qualidade da educação foi associada à qualidade dos docentes, diretores e aos demais servidores da escola. Importante destacar algumas medidas que estavam no documento da reforma educacional que já estavam em execução. Neste caso, já existiam o curso preparatório para os candidatos a diretor, ocorrendo na sequência avaliação, os aprovados na avaliação criavam um plano educacional para as escolas, permitindo que a comunidade pudesse ter informações para as eleições, os diretores tiveram um aumento de $45 \%$ nas gratificações. No campo das propostas, tinha como meta a valorização da carreira do profissional da educação e nesta visão defendia-se a o pagamento do piso, através de parcerias com o governo federal e racionalizaçãodos gastos para a efetivação do piso; tornar a carreira mais atrativa para os docentes; reorganização do estágio probatório com a intenção de conseguir uma avaliação correta e melhoria das práticas de ensino do professor; analisar as formas e mecanismo de promoção com vistas ter o caráter do mérito valorizado.

Destacava-se a criação de uma escola de formação de professores para desenvolver formações tendo como base as dificuldades constatadas na rede educacional estadual;salientava-se métodos, metodologias inovadoras e práticas; estabelecer cursos regulares com certificação e regulamentação. Um dos itens descrevia a academia de lideranças, que chamava a atenção para o papel do líder educacional e talentos nas escolas; novamente aqui se repete a necessidade de métodos inovadores com o uso metodologias para a preparação de líderes, tendo como suporte estudos de residência,coachinge de caso. Outro aspecto era a residência educacional, onde as escolas de referência seriam um exemplo e um modelo para a preparação de novos professores; explicava que no estágio probatório tivesse um programa de residência como uma fase necessária.

O segundo pilar da Reforma Educacional definia a adoção de práticas de ensino de alto impacto no processo de aprendizagem. $\mathrm{Na}$ introdução deste componente, explica que no começo do ano de 2011, constatou-se que nas áreas básicas do conhecimento, verificou-se mais de 1000 
diferentes componentes curriculares. Chamava atenção ainda para o aprendizado insatisfatório dos estudantes nas disciplinas de Matemática e Língua Portuguesa, conteúdos que são o suporte para as outras áreas do conhecimento. Para que esse quadro mudassedefendia-se a recuperação do espaço de aprendizagem e revisão do perfil burocrático de várias funções dos profissionais da educação.

No item que tratava do que já tinha sido feito, chamava-se a atenção para o trabalho pedagógico desempenhado pelos coordenadores pedagógicos, que já vinham sendo treinados em formação continuada e que exercia uma função de reprodução da ideologia da Secretaria Estadual de Educação. Este coordenador teve sua carga horária alterada de 30 horas para 40 horas. No espaço reservado para a proposta da reforma, explicava-se a necessidade de currículo mínimo, com uma base comum; materiais didáticos, com material de apoio ao professor, banco de aulas. Em outro aspecto, tratava-se da tutoria pedagógica que ocorreria através do chamado coaching pedagógico, que seria formado por uma equipe de tutores que treinariam os coordenadores pedagógicos e estariam acompanhando o cotidiano da escola; realizar uma reestruturação das subsecretarias com suas funções voltadas principalmente para o pedagógico. O novo ensino médio também era uma diretriz importante, defendendo um novo modelo para o ensino médio e viabilizar mais aprendizado e menos desistências dos alunos. Enfatizavam-se programas especiais para o ensino médio e o ensino profissionalizante. Outro ponto destacado era a criação de uma rede de colaboração com um portal pedagógico com trocas de experiências, um banco de práticas de gestão, exercícios e de aulas. Mostrar as boas práticas e bons resultados, reconhecendo os que fazem a diferença. Defendia-se o investimento em TI como soluções para a aprendizagem, com o programa um computador por aluno (UCA).

O terceiro pilar da reforma educacional tinha como meta a redução significativa da desigualdade educacional. $\mathrm{Na}$ introdução dessa meta, destacava-se que a redução da desigualdade educacional hoje significará a redução da desigualdade social amanhã. Argumentava o documento que uma das causas do desnível educacional era a reprovação, que acaba contribuindo para a distorção entre idade e série. Nesta questão, não tinha sido feito nada. No item de proposta da reforma, apresentava-se o programa de apoio às escolas vulneráveis, com suporte pedagógico especial, material de apoio ao ensino, a concessão de bônus para docentes que se voltam principalmente para alunos que mais precisam, direcionar uma parte do programa residência para as escolas vulneráveis. Destacava-se a atenção a redução da distorção da idade-série, com foco na alfabetização, redução do analfabetismoe a 
implementação de programas de aceleração de aprendizado. Outro aspecto destacado é o da redução da evasãoe reprovação escolar. A estratégia proposta foi a de monitoramento da frequência do aluno em tempo real através da internet, das tecnologias e utilizar programas de nivelamento para evitar as reprovações. Outra diretriz elencada foi $\mathrm{o}$ apoio a diversidade, propôs o ensino especial (Goiás tem experiência nessa área) com a melhoria da aprendizagem para o aluno especial; o ensino profissionalizante para jovem que vive no campo; a educação indígena e das minorias.

O quarto pilar da Reforma Educacional, possui como objetivo a estruturação do sistema de reconhecimento e remuneração por mérito. $\mathrm{Na}$ introdução, busca-se justificar a meritocracia, a premiação com bônus para aqueles docentes que conseguem bons resultados que melhoram o aprendizado dos alunos. No segundo elemento que se trata do que já foi feito, destacava-se o lançamento do Programa Reconhecer, que premiava os professores que estivessem em sala com frequência de acordo com os critérios estabelecidos pela Secretaria de Educação, receberiam uma bonificação. Também chama a atenção o Prêmio Escola, que premeia as unidades escolares com alto desempenho no IDEB 2011 e na avaliação padronizada do Estado com um valor financeiro. $\mathrm{O}$ terceiro elemento, trata do que a reforma propõe, é apresentado Índice de
Desenvolvimento da Educação Goiana (IDEGO),um indicador criado como ferramenta própria de avaliação que permitirá acompanhar e mensurar o sistema estadual. Fazendo parte do IDEGO, tinham o fluxo e a equidade, que em sua organização, observa o fluxo dos estudantes, como no IDEB. OIDEGO acompanha a questão da distribuição de desempenho dos alunos e não somente a média global. Quanto menos for a quantidade de alunos em condições insatisfatórias de aprendizagem, melhor estará a escola. Esta definição incentivará a atenção aos alunos que mais precisam. $\mathrm{O}$ índice sob o aspecto socioeconômico, disponibilizará, no futuro o elemento socioeconômico na performance das atividades das escolas.

Outra criação foi o Sistema de Avaliação do Estado de Goiás (SAEGO), criado para ser aplicado anualmente em toda a rede estadual com a intenção de avaliar os discentes das disciplinas de Matemática e Língua Portuguesa. Outro elemento era o bônus para os servidores como consequênciada educação por mérito, estabelecendo-se um círculo eficiente no objetivo do desempenho bom. Sendo o bônus estendido aos demais servidores que contribuem direta ou indiretamente para o bom aprendizado dos alunos. Outra proposta era o prêmio aluno, que premiava os alunos com bom desempenho. Educadores do ano também foi outra criação que buscava premiar e reconhecer o trabalho de alunos, professores 
e gestores que contribuem de forma significativa para o bom aprendizado.

O quinto pilar tinha como objetivo, a realização profunda de uma reforma na gestão e na infraestrutura da rede estadual de ensino. $\mathrm{Na}$ introdução deste item, explica-se o diagnóstico realizado pela Secretaria Estadual de Educação no início de 2011, sobre a gestão e a infraestrutura. Nesta análise, perceberam que as atividades burocráticas eram predominantes e não direcionada para o aluno. Nas finanças foram encontrados problemas seríssimos, observam que o gasto com a folha de pagamento chegavam a quase $90 \%$. Outro problema verificado foi a da infraestrutura das escolas que necessitavam de investimentos altos.

No item que trata do que já foi feito, explicam o programa Edificar,que era uma parceria da Agência Goiânia de Transportes e Obras (AGETOP) e da Secretaria de Educação, com vistas a ações de reformas de escolas. Destacava-se também a modernização da gestão da Secretaria de Educação com o objetivo de ser mais eficiente e utilização do recurso de uma forma melhor. No terceiro elemento que trata do que a reforma propõe, o item integração dos municípios procura incentivar à municipalização do ensino fundamental com um processo progressivo de retorno e dando apoio a esses municípios. Premiar as escolas municipais com bom desempenho na avaliação. Oferecer material de apoio e suporte aos professores dos municípios. Fornecer assessoria na área de gestão às secretárias municipais de educação que se interessarem.

Outro elemento deste pilar trata da excelência em infraestrutura com a busca por mecanismos mais eficientes de reforma e construção de escolas, pequenos reparos. A otimização dos gastos tinha a intenção economizar e dar uma nova orientação aos gastos. A meta era otimizar com a racionalização de gastos na educação estadual. Outro ponto, é o que trata da excelência em gestão com processos eficientes, agilidade para atender o estudante e os objetivos traçados. O acompanhamento de aluno ao longo da educação básica e um sistema de monitoramento. A elaboração de boletins de desempenho disponíveis para a sociedade. O último ponto propunha a escola modelo e comunidade, com um foco pedagógico claro e objetivo. Buscando a revisão de processos com vistas a otimização dos aspectos financeiros, operacionais e pedagógicos. Possuindo um manual de referência com um padrão de funcionamento e casos de sucesso para servir de norte as escolas.

\section{AS CONSONÂNCIAS DA REFORMA E DO PACTO EDUCACIONAL COM O CAPITAL}

A reforma e o pacto educacional estavam em sintonia com as ideias de Gustavo 
Ioschpe (2014), que explica que no ano de 2002 quando fazia seu mestrado em Economia, na área de Economia da Educação, chegou a três conclusões: primeira, no Brasil a educação foi e continua um desastre. $\mathrm{O}$ nosso país possui um nível médio de desenvolvimento e temos um sistema educacional de um padrão de país indigente. Segunda, não entraríamos na Era do conhecimento e não seríamos um país desenvolvido por causa de nossa defasagem educacional, isso acabaria com as nossas chances. A terceira, pouca gente trata da questão educação e desenvolvimento, e os que discutem fazem o diagnostico correto, mas se enganavam com a receita. Acreditavam que resolveriam os problemas investindo mais dinheiro no sistema, principalmente elevando substancialmente os salários dos docentes.

O Secretário Estadual de Educação Thiago Peixoto,em seu livro (2010), abordou a temática educação e desenvolvimento, e o quanto o conhecimento contribui como ferramenta para mobilidades social. A renda de cada pessoa, a chance de melhoria na carreira profissional está associada a cada ano de estudo realizado corretamente. Assim sendo, o conhecimento necessita se ampliado para mais indivíduos, consequentemente mais pessoas terão uma elevação em sua renda e como decorrência desse processo, a economia vai elevar-se. Temos claramente uma conexão da educação com uma economia desenvolvida. Sustenta que precisamos ultrapassar a questão filosófica e pedagógica presente nas questões educacionais e deslocar toda a atenção para a discussão de uma educação como algo que deve estar presente na questão do desenvolvimento do país.

Os 5 pilares e as diretrizes defendidas no reforma e pacto educacional em Goiás, iam muito mais do que aprender e ler escrever corretamente e o domínio das operações matemáticas. Em uma análise de caráter dialético percebemos que o discurso conservador sobre qualidade na esfera educacional conjecturou uma relação que pode ser entendida em uma forma que Gentili (1994) chama de duplo processo de transição, que no primeiro momento teve a questão da mudança do problema da democratização para o da qualidade e no segundo momento, houve deslocamento dos conteúdos que tipificam o debate sobre qualidade na área produtivoempresarial para o âmbito das políticas educacionais e para a avaliação dos processos didático-pedagógicos.

O conhecimento e a educação são compreendidos sob a ideologia do capitalismo global, como força motora e bases da modificação produtiva e progresso econômico. Sendo assim, bens econômicos fundamentais à transformação do processo de produção, da capacidade de ampliação científica e tecnológica, da elevação do lucro e do poder da disputa em uma concorrência de mercado que procura ser globalizada e livre. Dessa forma, constatamos visivelmente, as 
desenvolvimento-desempenho da economia. (LIBÂNEO; OLIVEIRA;TOSCHI， 2003, p.110).

Foram criados planos, programas e projetos para o sistema educativo e escolas com a finalidade de melhorar a qualidade do ensino. Entretanto, no fundo percebeu-se o intuito de assegurar as condições de fomento a produtividade, competição, eficiência almejados e reivindicados pelo mercado. Visivelmente temos um parâmetro de mercado para a relação ensino e aprendizagem com base no conceito de qualidade total, identificado com as diretrizes do mercado de trabalho e das novas organizações produtivas no mundo e em Goiás.

\section{CONSIDERAÇÕES FINAIS}

Os cinco pilares são as vigas mestre que conduzem a reforma educacional. $\mathrm{O}$ primeiro, é a valorização e fortalecimento do profissional da educação. Esta ação não ocorreu. O que aconteceu foi uma política de bonificação para os educadores que não faltavam ou tinham certo limite de porcentagem de faltas e também entregasse o planejamento quinzenal com conteúdo e estratégias de ensino no prazo estipulado. O segundo, foi a adoção de ensino de alta aprendizagem. Quanto a este item aconteceram cursos de capacitação basicamente para professores de Língua
Portuguesa e matemática, sendo outras áreas não atendidas. Importante destacar o resultado do IDEB de 2014, onde Goiás ficou em primeiro lugar no Ensino Médio. Relevante também observarmos que o IDEB em seu resultado não reflete a complexidade da realidade escolar em seu processo de ensino e aprendizagem e sua comunidade circundante, mas deve ser levado em consideração. O terceiro pilar foi reduzir significativamente a desigualdade educacional,o documento da reforma defende que as causas do desnível educacional era a reprovação, que acaba contribuindo para a distorção entre idade e série. Os avanços nessa área foram poucos $\mathrm{e}$ neste momento precisamos de mais dados quantitativos e qualitativos para nos debruçarmos sobre essa questão (pesquisa em andamento). Mesmo com a implementação do Programa de Intensificação de Aprendizagem os ganhos foram limitados. O quarto diz respeito a estruturação de um sistema de reconhecimento e remuneração por mérito Programa Reconhecer. Neste caso tratar o processo de ensino e aprendizagem, a presença do docente na escola, a partir de um valor pecuniário atrelado ao desempenho do professor é conceber e tratar a escola em lógica empresarial produtiva.O quinto pilar diz respeito a realizar uma profunda reforma na gestão e na infraestrutura da rede estadual de ensino.Quanto à gestão, constamos diversas diretrizes, programas e projetos que procuraram criar um sistema estadual de 
educação com escolas que eram estimuladas a adotar diversas técnicas de administração, capacitação e treinamento. Devido ao fato de termos mais de mil escolas estaduais não é possível verificar o resultado dessas propostas. Sobre a infraestrutura verificamos que ocorreu um expressivo investimento quantitativo e com um valor significativo. Mas, pelo fato de existirem mais de mil unidades escolares em Goiás, não é possível verificarmos a questão da qualidade na infraestrutura e se realmente contribuiu para espaços educativos adequados para a realização do processo de ensino, aprendizagem e outras atividades pedagógicas.

Os programas de bonificação para professor e o prêmio-poupança para alunos que tiveram um bom desempenho nas avaliações da Secretaria Estadual de Educação,mostram o caráter e os valores da reforma da reforma e do pacto educacional, onde o processo de ensinar e aprender passaram a ser orientados pela premiação pecuniária, o conhecimento e o saber, estabeleceu-se tendo como meio e fim a premiação financeira e não pela sua importância para a vida, para a cidadania e como um instrumento e ferramenta de construção de desenvolvimento econômico, político e social. Deve-se enfatizar que a palavra cidadania nem consta no documento oficial da reforma e do pacto educacional.

\section{REFERÊNCIAS}

BRANDÃO, Carlos Rodrigues. O que é educação. 33ed. São Paulo: Brasiliense, 1995.

FERREIRA, Adriano de Melo. A Inovação nas Políticas Educacionais no Brasil: Universidade e Formação de Professores. 2013. 305f. Tese (Doutorado em Educação). Faculdade de Educação da UniversidadeFederal de Goiás, Goiânia.

FONSECA, Marília. O Banco Mundial e a Educação: reflexões sobre o caso brasileiro. IN: GENTILI, Pablo (Org.). Pedagogia da exclusão. Petrópolis, RJ. Vozes, 1995.

GENTILI, Pablo A.A. O Discurso da Qualidade como Nova Retórica Conservadora no Campo Educacional. IN: GENTILI, Pablo A.A; SILVA, Tomaz Tadeu (Orgs.).

Neoliberalismo, Qualidade Total e Educação. 3ed. Petrópolis, RJ: Vozes, 1994.

GENTILI, Pablo A.A. Adeus àEscola Pública: a Desordem Neoliberal, a Violência do Mercado e o Destino da Educação das Maiorias. IN: GENTILI, Pablo A. A.(Org.). Pedagogia da Exclusão. Petrópolis, RJ. Vozes, 1995.

IOSCHPE, Gustavo. O que o Brasil que ser quando crescer? $1^{a}$ ed. Rio deJaneiro:

Objetiva, 2014

LIBÂNEO, José Carlos; OLIVEIRA, João Ferreira de; TOSCHI, MirzaSeabra. Educação Escolar: políticas, estrutura e organização. São Paulo: Cortez, 2003.

PEIXOTO, Thiago. Educação: o desafio de mudar. Goiânia: Kelps, 2010.

RAMOS, Cosete. Excelência da Educação. Rio de Janeiro, Qualitymark Ed, 1992.

Pedagogia da Qualidade Total. Rio de Janeiro, Qualitumark Ed, 1994.

Secretaria Estadual de Educação de Goiás. Versão online. Disponível em: http://www.seduc.go.gov.br/especiais/pactope laeducacao/pilares.asp. Acessado em 15/04/2015. 
Secretaria Estadual de Educação de Goiás. Versão online. Disponível em: http://www.see.go.gov.br/especiais/pactopela educação/pilar.asp. Acessado em 15/04/2015.

SILVA, Maria Abádiada. Do Projeto Político do Banco Mundial ao Projeto Politico da Escola Publica Brasileira. IN: Cad. Sedes, Campinas, v.23, n 61, p.283-301, dezembro de 2013. Disponível em

http://www.cedes.unicamp.br. Acessado em 23/07/2015.

SILVA, SimôniaPeres da. O Processo de Implementação das Políticas Educacionais e Repercussões nas Formas de Gestão da Escola e no Processo de ensinoaprendizagem: o Pacto pela Educação em Goiás. 2014. 248f. Tese (Doutorado em Educação). Pontifícia Universidade Católica de Goiás, Goiânia.

TODOS PELA EDUCAÇÃO. Disponível em: http://www.todospelaeducacao.org.br/quemsomos/o-tpe/ . Acessado em 20/07/2015.

TORRES, Carlos Alberto. Estado, Privatização e Política Educacional. IN: GENTILI, Pablo (Org.). Pedagogia da exclusão. Petrópolis, RJ. Vozes, 1995.

UNESCO, Relatório para UNESCO da Comissão Internacional sobre Educação para o século XXI. Educação: um tesouro a descobrir. $3^{\mathrm{a} e d . ~ S a ̃ o ~ P a u l o: ~ C o r t e z ; ~ B r a s i ́ l i a, ~}$ DF: MEC; UNESCO, 1999.

Notas:

1-Este artigo foi produzido com base na dissertação que desenvolvo no Mestrado Interdisciplinar Territórios e Expressões Culturais no Cerrado (TECCER), da Universidade Estadual de Goiás, sob a orientação da Dra. Divina Aparecida Leonel Lunas. 